\title{
PRODUCTION OF QUINOLINE-2-METHANOL AND QUINOLINE-2-METHANOL ACETATE BY A NEW SPECIES OF KITASATOA, KITASATOA GRISEOPHAEUS
}

\author{
Satoshi Ōmura, Yuzuru Iwai, Yōko Suzuki, Juichi Awaya, \\ YAeKo Konda and Masayuki Onda \\ Kitasato University and The Kitasato Institute \\ Minato-ku, Tokyo 108, Japan \\ (Received for publication May 25, 1976)
}

\begin{abstract}
Two metabolites have been isolated from the fermentation broth of a new species of Kitasatoa, Kitasatoa griseophaeus. These alkaloids have been identified as quinoline-2methanol and quinoline-2-methanol acetate. The former exhibits hypoglycemic activity in the rat.
\end{abstract}

In the previous articles ${ }^{1)}$, we described a method for screening for alkaloids produced by microorganisms and reported the new alkaloids pyrindicin ${ }^{1)}$, NA-337 $\mathrm{A}^{2)}$ and TM-64). In the course of the screening, we found in addition two alkaloids produced by the soil isolate PO-1227. Strain PO-1227 was classified as a new species of Kitasatoa, Kitasatoa griseophaeus. Both alkaloids were shown to be quinoline alkaloids and were identified as quinoline-2-methanol ${ }^{4)}$ and quinoline-2-methanol acetate ${ }^{5)}$.

It has been reported that quinoline alkaloids are produced by Pseudomonas sp. and fungi ${ }^{6)}$. However, there has been no report describing production of this group of alkaloids by actinomycetes. Consequently, this was the first observation of the production of quinoline-2-methanol and its acetate derivative by a microorganism.

The present paper deals with the taxonomy of the producing strain, as well as the production, isolation, identification and pharmacological activities of these alkaloids.

\section{Taxonomy}

\section{Morphological Characteristics}

Strain PO-1227 was cultured on glycerol-asparagine agar and oatmeal agar for 14 days at $27^{\circ} \mathrm{C}$ and observed microscopically. Its morphological characteristics were as follows: The aerial mycelium was $0.8 \sim 1.2 \mu$ in diameter, showing straight and irregular branching (Fig. 1A). It formed no spirals or whorls, but had many spore chains resembling Streptomyces species (Fig. 1B). It also had sticklike sporangia (Fig. 2A) with motile spores (zoospores). The spores were $1.0 \sim 1.2 \mu \times 0.6 \sim 0.7$ $\mu$ in size, oval with smooth surfaces. The formation of zoospores was very scanty and these zoospores were less motile in comparison with zoospores of known Kitasatoa species. Fig. 2B illustrates an electronmicrograph of the zoospores, $0.2 \mu \times 1.4 \mu$ in size, with several flagella. In contrast zoospores of known Kitasatoa species have a single polar flagellum.

\section{Cultural Characteristics}

The culture was observed after incubation at $28^{\circ} \mathrm{C}$ for two weeks, except where otherwise noted. Color names and hue numbers indicated are those of the Color Harmony Manual (4th edition) published by Container Cooperation of America. The cultural characteristics of strain PO-1227 are summarized in Table 1. 
Fig. 1. Sporophores (A) and spores (B) of strain PO-1227. (A: Inorganic salts-starch agar, 14 days at $27^{\circ} \mathrm{C}, \times 1,000 ; \mathrm{B}$ : Glycerol-asparagine agar, 14 days at $27^{\circ} \mathrm{C} \times 14,400$ )

(A)

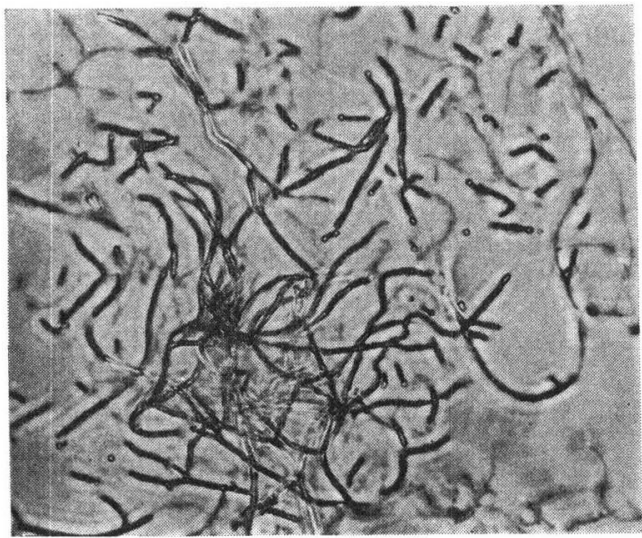

(B)

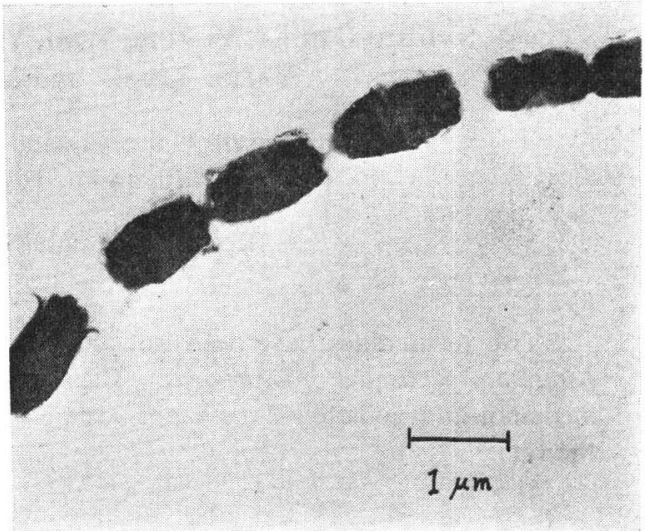

Fig. 2. Sporangia (A) and zoospore (B) of strain PO-1227 (Water agar 10 days at $27^{\circ} \mathrm{C}, \mathrm{A}: \times 1,000$, B: $\times 35,000)$

(A)

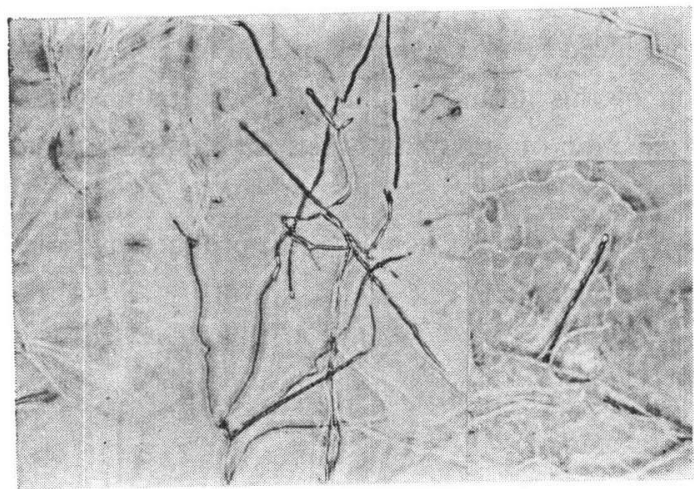

(B)

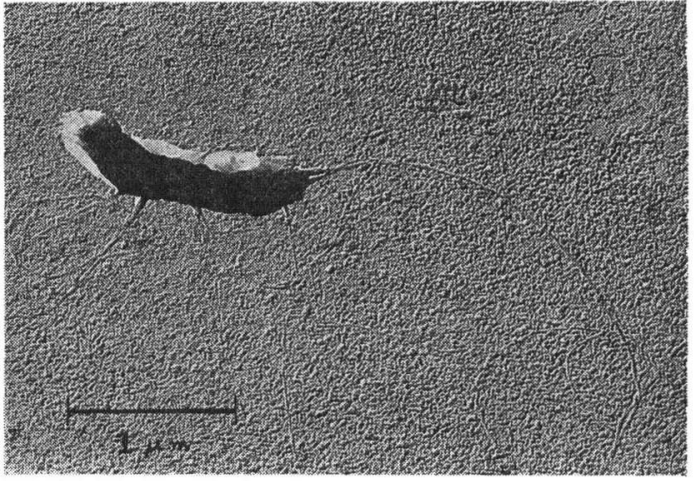

Table 1. Cultural characteristics of strain PO-1227.

\begin{tabular}{|c|c|c|c|}
\hline & Growth & Aerial mycelium & Soluble pigment \\
\hline Sucrose-nitrate agar & colorless & poor, 2dc (Natural) & - \\
\hline Glucose-nitrate agar & 2ic (Light Gold) & - & 3ng (Yellow Maple) \\
\hline Glycerol-calcium malate agar & 21e (Mustard) & $\begin{array}{l}\text { powder, 2ea (Light } \\
\text { Wheat) }\end{array}$ & - \\
\hline Glucose-asparagine agar & $2 \mathrm{gc}($ Bamboo $)$ & cottony, white & 2ne (Mustard Gold) \\
\hline Glycerol-asparagine agar & colorless & poor, white & - \\
\hline Inorganic salts-starch agar & colorless & poor, 2cb (Ivory Tint) & 3ie (Camel) \\
\hline Tyrosine agar & 2ic (Light Gold) & poor, white & 2ng (Yellow Maple) \\
\hline Nutrient agar & 2ea (Light Wheat) & - & - \\
\hline Peptone-yeast iron agar & 2ca (Light Ivory) & - & - \\
\hline Yeast extract-malt extract agar & 2ea (Light Wheat) & poor, 2dc (Natural) & 3ng (Yellow Maple) \\
\hline Oat meal agar & 2ea (Light Wheat) & poor, white & 2pg (Mustard Gold) \\
\hline
\end{tabular}


Table 2. Physiological characteristics of strain PO-1227.

\begin{tabular}{l|c||l|l}
\hline & Response & & Response \\
\hline Melanin formation & - & Carbon utilization & \\
Tyrosinase reaction & - & Arabinose & + \\
Nitrate reduction & + & Xylose & + \\
Liquefaction of gelatin & + & Glucose & + \\
Coagulation of milk & - & Fructose & + \\
Peptonization of milk & + & Sucrose & + \\
Hydrolysis of starch & + & Inositol & - \\
Temperature range for growth & $15 \sim 40^{\circ} \mathrm{C}$ & Rhamnose & - \\
& & Raffinose & - \\
\hline
\end{tabular}

Table 3. Comparison of strain PO-1227 with known Kitasatoa species.

\begin{tabular}{|c|c|c|c|c|}
\hline & & PO-1227 & $\begin{array}{c}\text { K. nagasakiensis } \\
\text { KA-281 }\end{array}$ & $\begin{array}{l}K . \text { diplospora } \\
\mathrm{KA}-280\end{array}$ \\
\hline Zoospore & & $\begin{array}{c}\text { rod single or in pairs, } \\
1.4 \times 0.2 \mu\end{array}$ & $\begin{array}{l}\text { rod single or in pairs } \\
2.4 \sim 5.0 \times 1.1 \sim 1.35 \mu\end{array}$ & $\begin{array}{l}\text { ellipsoidal single or in } \\
\text { pairs, } 2.5 \sim 3.0 \times 1.5 \mu\end{array}$ \\
\hline Conidia & & $\begin{array}{l}\text { oval, smooth, } \\
1.0 \sim 1.2 \times 0.6 \sim 0.7 \mu\end{array}$ & $\begin{array}{l}\text { ellipsoidal, smooth, } \\
1.2 \sim 1.6 \times 0.8 \sim 1.0 \mu\end{array}$ & $\begin{array}{l}\text { cylindrical, smooth, } \\
1.3 \sim 1.5 \times 0.7 \mu\end{array}$ \\
\hline $\begin{array}{l}\text { Glycerol- } \\
\text { asparagine } \\
\text { agar }\end{array}$ & $\begin{array}{l}\text { G } \\
\text { AM } \\
\text { SP }\end{array}$ & $\begin{array}{l}\text { colorless } \\
\text { white } \\
\text { 3ic (Light Amber) }\end{array}$ & $\begin{array}{l}\text { 3ng (Light Brown) } \\
\text { white } \rightarrow 5 \mathrm{ca} \text { (Shell Pink) } \\
\text { 4ng (Light Brown) }\end{array}$ & $\begin{array}{l}11 / 2 \mathrm{gc} \text { (Dusty Yellow) } \\
\text { white } \\
\text { 3ie (Camel) }\end{array}$ \\
\hline $\begin{array}{l}\text { Inorganic } \\
\text { salts-starch } \\
\text { agar }\end{array}$ & $\begin{array}{l}\text { G } \\
\text { AM } \\
\text { SP }\end{array}$ & $\begin{array}{l}\text { colorless } \\
\text { 2ig (Slate Tan) } \\
\text { 3ne (Topaz) }\end{array}$ & $\begin{array}{l}\text { colorless } \\
\text { white } \rightarrow 5 \mathrm{ec} \text { (Dusty Peach) } \\
2 \mathrm{gc} \text { (Bamboo) }\end{array}$ & $\begin{array}{l}\text { colorless } \\
\text { 5ca (Shell Pink) } \\
\text { 2gc (Bamboo) }\end{array}$ \\
\hline $\begin{array}{l}\text { Oat meal } \\
\text { agar }\end{array}$ & $\begin{array}{l}\text { G } \\
\text { AM } \\
\text { SP }\end{array}$ & $\begin{array}{l}\text { colorless } \\
\text { white } \\
\text { 2pg (Mustard Gold) }\end{array}$ & $\begin{array}{l}\text { colorless } \\
\text { 5dc (Pussywillow Gray) } \\
\text { 3ie (Camel) }\end{array}$ & $\begin{array}{l}\text { colorless } \\
\text { grayish white } \\
\text { 31e (Cinnamon) }\end{array}$ \\
\hline
\end{tabular}

3. Physiological Characteristics

Utilization of carbon sources by strain PO-1227 was investigated according to the method of Pridham and GotTlieb ${ }^{7)}$. Excellent growth was observed when arabinose, xylose, glucose, fructose and sucrose were used. The physiological characteristics of strain PO-1227 are summarized in Table 2.

Using the procedures described by BECKER et al., ${ }^{8)}$ the cell wall components of strain PO-1227 were analyzed with the following results: positive for LL type of diaminopimelic acid and ambiguous for the mesoisomer. Glycine was detected, but arabinose and galactose were not present.

From the above results, it was concluded that strain PO-1227 is a Kitasatoa species ${ }^{\ominus)}$. Strain PO1227 was then compared with type cultures of the four known Kitasatoa species: K. purpurea, K. diplospora, $K$. kauaiensis and $K$. nagasakiensis. Morphological, cultural and physiological characteristics of strain PO-1227 resembled those of K. nagasakiensis and K. diplospora. However, the former is nonchromogenic while the latter two are chromogenic. Taxonomic comparison of strain PO-1227 with these species is summarized in Table 3.

Based on the differences noted, strain PO-1227 is assigned to a new species of Kitasatoa and is designated as Kitasatoa griseophaeus. Strain PO-1227 has been deposited with the Fermentation 
Research Institute, Agency of Industrial Science and Technology with the accession number FERM-P No. 3077.

\section{Production}

Strain PO-1227 was maintained on modified WAKSMAN's agar or as freeze-dried stock. The stock culture was inoculated into $100 \mathrm{ml}$ of medium in a SAKAGUCHI flask and incubated at $27^{\circ} \mathrm{C}$. A 48-hour culture was transferred into 20 liters of medium in a 30-liter jar fermentor and the fermentation was carried out for 3 days under the following conditions: temperature, $27^{\circ} \mathrm{C}$; aeration, 10 liters $/ \mathrm{min}$; agitation, 250 r.p.m.; and pressure, $0.5 \mathrm{~kg} / \mathrm{cm}^{2}$. The composition of the seed medium was $2 \%$ glucose, $0.5 \%$ peptone, $0.5 \%$ meat extract, $0.3 \%$ dried yeast, $0.3 \% \mathrm{CaCO}_{3}(\mathrm{pH} 7$ before sterilization) and that of the production medium was $1 \%$ glucose, $2 \%$ starch, $0.5 \%$ yeast extract, $0.5 \%$ peptone and $0.4 \% \mathrm{CaCO}_{3}$ (pH 7 before sterilization). Adekanol LG-109 (Asahi Electro-Chemical Co., Ltd.,) was used as antifoam agent. The titer of alkaloid in units was determined as the maximum dilution number of a DragendorfF positive solution ${ }^{1)}$. A typical time course of PO-1227 production in a 30-liter jar fermentor is shown in Fig. 3. The concentration of the alkaloids produced reached a maximum $72 \sim 80$ hours after inoculation and then gradually decreased.

Fig. 3. Time course of alkaloid PO-1227 production by Kitasatoa griseophaeus.

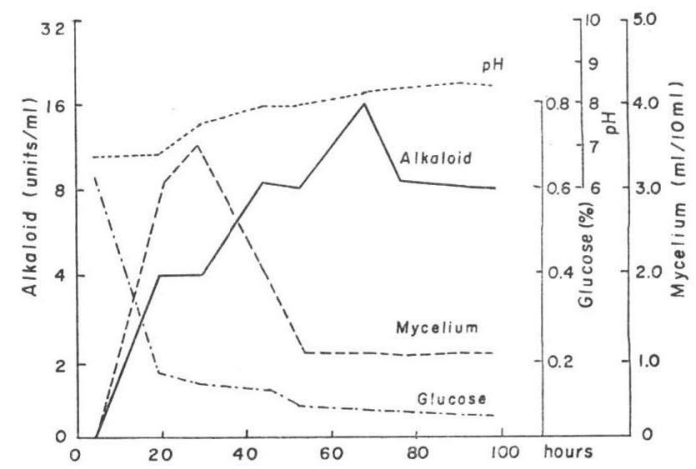

\section{Isolation}

Two alkaloids were detected on silica gel TLC upon eluting with $\mathrm{CHCl}_{3}-\mathrm{CH}_{3} \mathrm{OH}(10: 1, \mathrm{v} / \mathrm{v})$; these were designated as PO-1227 A ( Rf 0.7) and B ( Rf 0.4). Attempts to selectively produce A and B was unsuccessful with the former being the minor product in many cases. In the following cases, PO-1227 $\mathrm{A}$ and $\mathrm{B}$ were accumulated in almost equal amounts in the fermentation broth. Culture broth (20 liters) of Kitasatoa griseophaeus obtained by incubation in a 30-liter jar fermentor was used as a starting material. The presence of alkaloids was determined by the DRAGENDORFf reaction. After the broth supernatant was adjusted to $\mathrm{pH} 10$ with aqueous ammonia, the alkaloids were extracted with 4 liters $n$-butyl acetate and then transferred into 1.5 liters $0.1 \mathrm{~N}$ hydrochloric acid. The water layer was adjusted to $\mathrm{pH} 10$ with aqueous ammonia and extracted twice with 1 liter chloroform. The solvent layer was again transferred into $600 \mathrm{ml} 0.1 \mathrm{~N}$ hydrochloric acid. The water layer was adjusted to $\mathrm{pH}$ 10 with aqueous ammonia and extracted three times with $300 \mathrm{ml}$ ether. The ether solution was dried over anhydrous sodium sulfate, concentrated to a small volume, and then chromatographed on silica gel (15 g) eluting with a solvent mixture of benzene and acetone. Alkaloids PO-1227 A and B were successively eluted from the column and were separated from each other by column chromatography on silica gel. Each alkaloid fraction was concentrated to a small volume, to which a saturated solution of picric acid in ether was added until no more precipitates formed. Thus PO-1227 A picrate $(220 \mathrm{mg})$ and PO-1227 B picrate $(240 \mathrm{mg})$ were obtained. Each picrate was suspended in a mixture of $100 \mathrm{ml}$ chloro- 
form and $20 \%$ aqueous potassium hydroxide $(10 \sim 20 \mathrm{ml})$, and the mixture was vigorously shaken. The solvent layer was washed with water, dried over anhydrous sodium sulfate, and concentrated in vacuo to dryness. Each dried material was recrystallized from $n$-hexane to yield $120 \mathrm{mg}$ PO-1227 A and 140 mg PO-1227 B.

PO-1227 B melted at $67 \sim 68^{\circ} \mathrm{C}$ and its optical rotation showed $[\alpha]_{\mathrm{D}}^{20} 0(c 1.0$, methanol). Ultraviolet spectrum showed characteristic bands at $\lambda_{\max }^{\mathrm{MeOH}}, \mathrm{nm}(\varepsilon): 230(47,700), 233(44,500), 277(4,000), 284$ $(3,800), 290(3,700), 296(3,300), 302(4,000), 308(2,500), 317(5,000)$. Infrared absorption spectrum in $\mathrm{KBr}$ pellet exhibited characteristic bands at 3,200, 1,600, 1,500, 1,420, 1,310, 1,080, 820, 780 and 750 $\mathrm{cm}^{-1}$. The molecular formula $\mathrm{C}_{10} \mathrm{H}_{9} \mathrm{NO}$ for PO-1227 B was determined on the basis of elemental analysis and its mass spectrum. The elemental analysis of PO-1227 B picrate gave the following values: C 49.47, H 3.41, N $13.70(\%)$. The calculated values for $\mathrm{C}_{10} \mathrm{H}_{9} \mathrm{NO} \cdot \mathrm{C}_{6} \mathrm{H}_{3} \mathrm{~N}_{3} \mathrm{O}_{7}$ are $\mathrm{C} 49.52, \mathrm{H} 3.43$, and N 13.84. The mass spectrum of PO-1227 B showed $m / e 159.0690\left(\mathrm{M}^{+}\right)$. The characteristic cracking pattern of PO-1227 B suggested the presence of quinoline or isoquinoline skeleton. These spectroscopic properties (IR, PMR and Mass) suggested alkaloid PO-1227 B to be either quinoline-2-methanol ${ }^{4)}$ or isoquinoline-1-methanol ${ }^{10)}$. The melting point of both compounds in the literature were $66 \sim 67^{\circ} \mathrm{C}$ and $65^{\circ} \mathrm{C}$, respectively. Consequently, alkaloid PO-1227 B melted at $67 \sim 68^{\circ} \mathrm{C}$ was presumed to be quinoline-2-methanol.

\section{Identification}

The physico-chemical properties of PO-1227 B indicated that it is most likely to be quinoline-2methanol and its identity was confirmed by comparing it with an authentic sample prepared by independent synthetic methods ${ }^{11,12)}$.

Fig. 4. IR spectral comparison of alkaloid PO-1227-B with quinoline-2-methanol picrate.

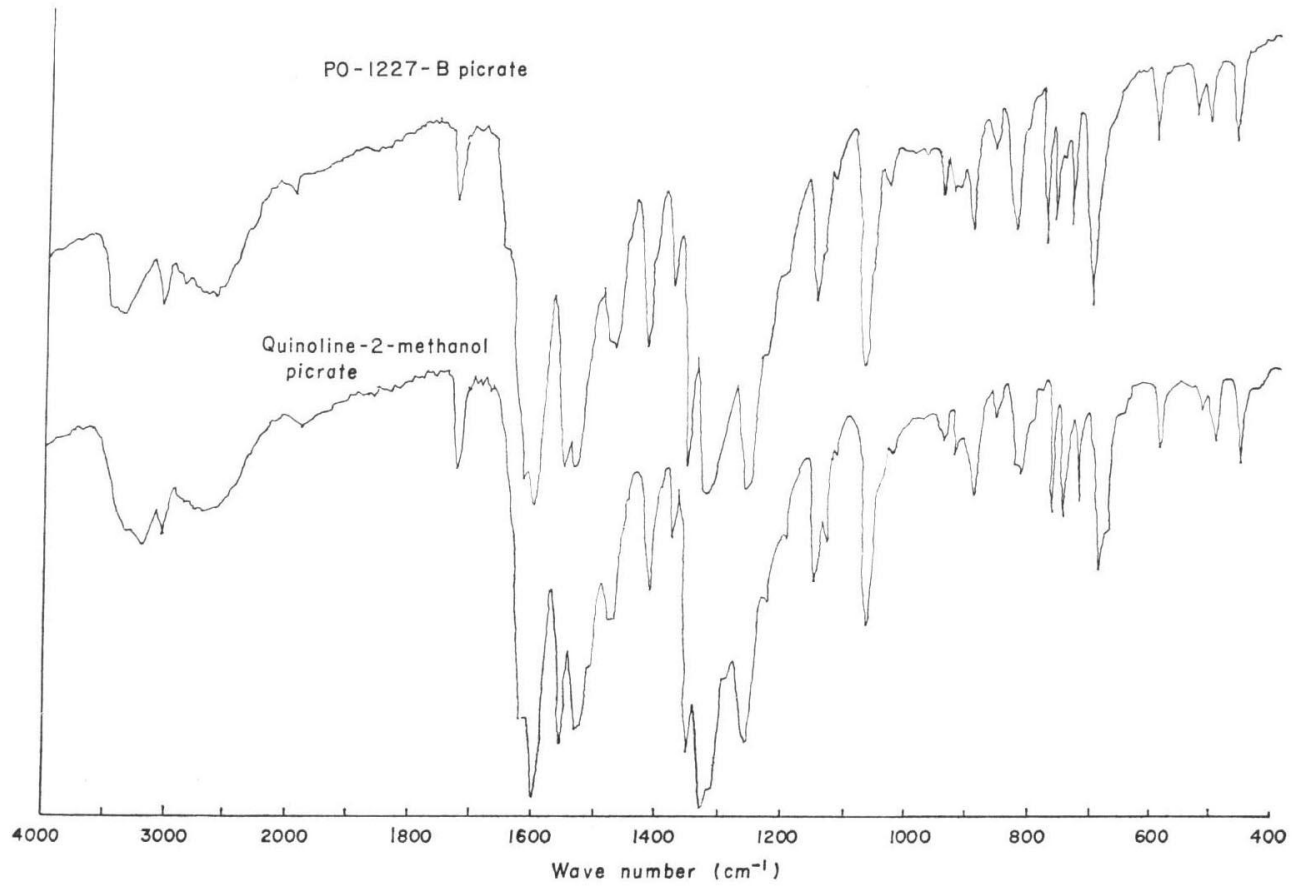


A mixture containing $1 \mathrm{~g}$ of quinaldine, $3 \mathrm{ml}$ of acetic acid and $1 \mathrm{ml}$ of a $30 \%$ aqueous hydrogen peroxide was heated at $50^{\circ} \mathrm{C}$ for 10 hours. After cooling in ice, $80 \%$ aqueous potassium hydroxide was added to the mixture and the solution shaken to afford precipitate. The resulting precipitate was recrystallized from water to yield $350 \mathrm{mg}$ quinaldine oxide; m.p. $77 \sim 78^{\circ} \mathrm{C}$. A mixture of $1 \mathrm{ml}$ acetic anhydride and $30 \mathrm{mg}$ of the quinaldine oxide were refluxed for 1 hour, to which ether and $10 \%$ aqueous sodium carbonate were then added. The resulting ether layer was concentrated in vacuo to give $20 \mathrm{mg}$ quinoline-2-methanol acetate. Twenty $\mathrm{mg}$ of the quinoline-2-methanol acetate was suspended in $1 \mathrm{ml}$ of $20 \%$ aqueous potassium hydroxide and the solution shaken for 1 hour. It was then extracted with ether. The ether layer provided $10 \mathrm{mg}$ quinoline-2-methanol.

Since the spectroscopic properties of the quinoline-2-methanol and its picrate were in complete agreement with those of alkaloid PO-1227 B and its picrate, respectively, as shown in Fig. 4, it was reasonably concluded that PO-1227 B is identical with quinoline-2-methanol.

The PMR $\left(\mathrm{CCl}_{4}\right)$ and IR ( $\left.\mathrm{KBr}\right)$ spectra of the quinoline-2-methanol acetate prepared by the above method were also compared with those of alkaloid PO-1227 A. As expected, these were completely identical. This observation as well as mixed melting point determination of the picrates unambiguously confirmed that PO-1227 A is identical with quinoline-2-methanol acetate.

\section{Pharmacological Activity}

When PO-1227 B was tested in a variety of pharmacological system, it was found to have hypoglycemic activity in the rat as shown in Table 4. The quinoline-2-methanol hydrochloride prepared by the following procedure and tolbutamide as control drug were used for this test. PO-1227 B picrate was made alkaline with $20 \%$ aqueous potassium hydroxide and treated with benzene. The benzene layer was dried over anhydrous $\mathrm{Na}_{2} \mathrm{SO}_{4}$, to which hydrogen chloride was introduced to give quinoline-2-methanol hydrochloride. Three Wistar male rats weighing approximately $110 \mathrm{~g}$ were administrated the compounds orally. Two hours before and after the administration of each drug, $0.1 \mathrm{ml}$ of blood was taken from the lateral caudal vein and the glucose concentration in each blood sample was assayed by the modified HOFFMAN method ${ }^{13)}$.

Table 4. Effect of quinoline-2-methanol on hypoglycemic activity in rat.

\begin{tabular}{l|c|c|c}
\hline \multicolumn{1}{c|}{ Compound } & $\begin{array}{c}\text { Dose } \\
(\mathrm{mg} / \mathrm{kg})\end{array}$ & $\begin{array}{c}\text { Exp. } \\
\text { No. }\end{array}$ & $\begin{array}{c}\text { Decrease of } \\
\text { glucose } \\
\text { level (\%) }\end{array}$ \\
\hline Quinoline-2-methanol & \multirow{3}{*}{100} & 1 & 23.1 \\
$\mathrm{HCl}$ & & 2 & 25.8 \\
Tolbutamide & 50 & 1 & 67.0 \\
& & 2 & 49.5 \\
Saline (control) & & 1 & 6.5 \\
& & 2 & 11.5 \\
\hline
\end{tabular}

\section{Discussion}

In subsequent screening for alkaloids from microorganisms, two actinomycetes strains, AM-2431 and AM-2435 were also found to produce quinoline-2-methanol. Strain AM-2431 was classified as Streptomyces species. The later organism was identified as Kitasatoa species, but differing from Kitasatoa griseophaeus strain PO-1227. It has been known that various quinoline alkaloids are present in nature and that a variety of organisms produce kynurenate and related compounds that are structurally similar to quinoline-2-methanol. Quinoline alkaloids are known to be produced by bacteria and fungi. For example, complex of seven related 4-oxyquinolines and one 4-quinolone has been elaborated by Pseudomonas aeruginosa. These are commonly called "pyo" compounds or pseudanes. It has also been reported that viridicatum, viridicatol and 3-O-methyl viridicatin are produced by 
Penicillium species. It is thus concluded that our findings are new in that both quinoline-2-methanol and its acetate are naturally occurring compounds and actinomycetes produce quinoline alkaloids.

\section{Acknowledgments}

The authors wish to thank Toyo Jozo Co., Ltd. for assay of biological activities, Dr. A. MATSUMAE for his kind advise. Thanks are also due to Mr. R. Masuma and Mrs. Y. TAKAHASHI for their assistance.

\section{References}

1) Ōmura, S.; H. Tanaka, J. Awaya, Y. Narimatsu, Y. Konda \& T. Hata: Pyrindicin, a new alkaloid from a Streptomyces strain. Taxonomy, fermentation, isolation and biological activity. Agr. Biol. Chem. 38: 899 906, 1974

2) Onda, M.; Y. Konda, Y. Narimatsu, H. Tanaka, J. Awaya \& S. Ōmura: Alkaloids from Streptomyces sp. NA-337. Chem. Pharm. Bull. 22: 2916 2920, 1974

3) Ōmura, S.; Y. Suzuki, C. Kitao, Y. TAKahashi \& Y. Konda: Isolation of a new sulfur-containing basic substance from a Thermoactinomyces species. J. Antibiotics 28: 609 610, 1975

4) TANIDA, H.: Synthesis of chloromethylquinoline from quinaldine 1-oxide and lepidine 1-oxide. Yakugaku Zasshi 78: 611 613, 1958

5) Furukawa, S.: Synthesis of pyridine derivatives. XI. On mechanism of rearrangement reaction of picoline 1-oxide derivatives with acetic anhydride. Yakugaku Zasshi 79: 492 499, 1959

6) Miller, M. W.: The Pfizer handbook of microbial metabolites. p. 492, McGraw-Hill, New York, 1961

7) Pridham, T. G. \& D. Gottlieb: The utilization of carbon compounds by some actinomycetales as an aid for species determination. J. Bact. 56: 107 114, 1948

8) Becker, B.; M. P. Lechevalier, R. E. Gordon \& H. A. Lechevalier: Rapid differentiation between Nocardia and Streptomyces by paper chromatography of whole cell hydrolysates. Appl. Microbiol. 12: 421 423, 1964

9) Matsumae, A.; M. Ohtani, H. Takeshima \& T. Hata: A new genus of the Actinomycetales: Kitasatoa gen. nov. J. Antibiotics 21: 616 625, 1968

10) Brown, B. R.; D. L. Hammic \& B. H. Thewlis: $\omega$-Halogenomethyl-pyridines, -quinolines, and -isoquinolines. I. Preparation. J. Chem. Soc. 1951: 1145 1149, 1951

11) Boekelheide, V. \& W. J. Linn: Rearrangements of N-oxides. A novel synthesis of pyridyl carbonols and aldehydes. J. Am. Chem. Soc. 76: 1286 1291, 1954

12) Pachter, I. J.: The benzoylation of quinaldine oxide. J. Am. Chem. Soc. 75: 3026 3027, 1953

13) Hoffman, W. S.: A rapid photoelectric method for the determination of glucose in blood and urine. J. Biol. Chem. 120: 51 55, 1937 